\title{
Avaliação da Resistência à Oxidação de Camadas de Ligação de Revestimentos Utilizados em Barreiras Térmicas ${ }^{\mathrm{a}}$
}

\author{
Maria Júlia Xavier Belém ${ }^{1}$, Hipólito Carvajal Fals², Carlos Roberto Camello Lima ${ }^{1}$ \\ 1 Faculdade de Engenharia, Arquitetura e Urbanismo, Universidade Metodista de Piracicaba - UNIMEP, Santa Bárbara d’Oeste, \\ SP, Brasil. \\ 2 Faculdade de Engenharia Mecânica, Universidade de Oriente, Santiago de Cuba, Cuba.
}

Recebido: 24 Nov., 2015

Aceito: 15 Dez., 2015

E-mails: mjbelem@unimep.br (MJXB), crclima@unimep.br (CRCL)

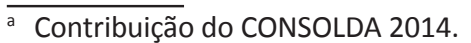

Este é um artigo publicado em acesso aberto (Open Access) sob a licença Creative Commons Attribution Non-Commercial, que permite uso, distribuição e reprodução em qualquer meio, sem restriçōes desde que sem fins comerciais e que 0 trabalho original seja corretamente citado.
Resumo: Revestimentos são crescentemente utilizados como alternativa de engenharia em projetos avançados. Diversas técnicas e processos estão disponíveis para a aplicação de revestimentos, dependendo da condição específica a que se destinam. Revestimentos para barreira térmica, conhecidos como TBC, fazem parte de uma série especial de revestimentos metal-cerâmicos com tradicional utilização na indústria aeronáutica e crescente aplicação nas indústrias automotiva e de turbinas industriais. Um dos maiores problemas dos TBCs é sua degradação devido à oxidação em alta temperatura da camada de ligação, levando à falha do revestimento por desplacamento. O presente estudo investiga e compara o comportamento de oxidação da camada de ligação de revestimentos para barreira térmica (TBC), tendo como material a liga NiAl, que é uma liga bastante utilizada devido a suas características em altas temperaturas e por ter uma boa adesão em vários substratos. A camada de ligação foi aplicada em um substrato de Aço ABNT 1020 pelo processo Flame Spray (Aspersão a chama). Para a realização dos testes de oxidação isotérmica, o forno utilizado foi regulado a uma temperatura de $1000^{\circ} \mathrm{C}$ em atmosfera de ar estático, com exposição das amostras por 24, 48, 96 horas e o resfriamento feito em ar atmosférico à temperatura ambiente. A análise do óxido crescido termicamente (TGO - Thermally Grown Oxide) em cada amostra foi feita relacionando os tempos de exposição, avaliando a taxa de óxidos por meio de medições de ganho de massa das amostras com revestimentos oxidados e análises por Microscopia Eletrônica de Varredura e Microscopia Ótica.

Palavras-chave: Revestimento; TBC; Barreira térmica; Aspersão térmica; Oxidação.

\section{Assessment of the 0xidation Resistance of Bond Coats Used in Thermal Barrier Coatings}

\begin{abstract}
Coatings are increasingly used as an alternative in advanced engineering projects. Coatings can be applied by various techniques and processes, depending on the specific condition as intended. Thermal Barrier Coatings, known as TBC, are part of a special series of metal-ceramic coatings with traditional use in the aviation industry and increasing application in the automotive and power generation turbine industries. They consist basically of two layers, a metallic bond coat and a ceramic top coat. A major problem is TBC degradation due to oxidation at high temperature of the bond coat, forming an oxide layer known as TGO, leading to complete failure of the coating. The present study investigates and compares the oxidation behavior of the a NiAl bond coat, which is one of the widely used materials due to its characteristics at high temperatures and good adhesion to various substrates. The bond coat was applied to an SAE 1020 steel substrate by Flame Spray. To achieve the isothermal oxidation tests, the furnace equipment was set to a temperature of $1000{ }^{\circ} \mathrm{C}$ in static air atmosphere, with exposure of the samples at 24,48 and 96 hours and cooling done in air at room temperature. Analysis of the thermally grown oxide (TGO) in each sample was performed by relating the exposure times, assessing the oxidation rate by measuring the mass gain of the samples with oxidized coatings and analysis by Optical and Scanning Electron Microscopy (SEM).
\end{abstract}

Key-words: Coating; TBC; Thermal barrier coating; Thermal spray; Oxidation.

\section{Introdução}

A crescente utilização de revestimentos depositados por diversos processos para proteção de componentes ou produtos metálicos, dentro da área conhecida como Surface Engineering, vem ganhando destaque em diversas indústrias, como nas indústrias petroquímica, aeronáutica e automobilística. Revestimentos são aplicados objetivando 
proteção contra desgaste, corrosão, compatibilidade biológica, entre outras finalidades [1]. Turbinas a gás e motores diesel operam em elevadas temperaturas e pressões, o que compromete a integridade estrutural dos seus componentes. A utilização de revestimentos especiais aplicados por processos distintos tornou-se uma técnica essencial para aumentar a vida útil ou mesmo a temperatura de trabalho destes componentes. A eficiência destes revestimentos é fortemente dependente, tanto dos materiais utilizados no revestimento, como do processo utilizado para obtê-los. Este tipo de revestimento é chamado de barreira térmica (Thermal Barrier Coating - TBC) devido a sua função específica [2].

TBC consiste, tipicamente, de uma camada de base, em geral MCrAlY, sendo M um metal específico, e um revestimento cerâmico externo. Este último age como um isolante térmico enquanto que a camada de ligação promove a aderência entre o substrato metálico e o revestimento externo cerâmico e proporciona proteção contra oxidação e corrosão a quente do substrato [1-3]. Os TBCs que trabalham em temperaturas superiores a $1000^{\circ} \mathrm{C}$ são produzidos a partir de zircônias estabilizadas com ítria, cálcia, magnésia ou céria, entre outros óxidos dopantes. Os revestimentos mais duráveis são aqueles obtidos com zircônias estabilizadas com 6 a $8 \%$ em peso de ítria conhecidos como YSZ (Ytria Stabilized Zirconia) [4-6].

$\mathrm{Na}$ indústria aeronáutica, estes revestimentos são um recurso efetivo e de custo relativamente baixo para aumentar a temperatura de operação das ligas metálicas usadas nas palhetas de turbinas e outros componentes. À medida que as pesquisas em novos materiais e o entendimento da microestrutura, propriedades mecânicas e térmicas progredirem, será possível a operação das turbinas a gás em temperaturas mais altas, com melhor desempenho, durabilidade e confiabilidade [3]. A aplicação dos revestimentos TBC na câmara de combustão e nas palhetas dos primeiros estágios de uma turbina pode reduzir o consumo de combustível entre 1 a $2 \%$, o que representa uma economia de até dezenas de milhões de dólares por ano para algumas companhias aéreas $[2,7,8]$. $O$ aumento da capacidade do isolamento térmico dos TBCs surge como um desafio técnico e econômico para a engenharia. A redução da condutividade térmica dos TBCs permite um aumento no desempenho das turbinas pela melhoria da eficiência de combustão, redução do consumo específico de combustível, além de contribuir para a redução da refrigeração interna e da temperatura das partes metálicas [9]

$\mathrm{Na}$ indústria automobilística, os revestimentos para barreira térmica em motores diesel protegem os componentes contra oxidação em altas temperaturas, reduzindo as temperaturas dos substratos e os efeitos da fadiga térmica e, via radiação, ajudam a converter mais calor em energia útil [10,11]. Em motores diesel, é necessário promover a redução nas perdas de calor entre a câmara de combustão e os outros componentes, para que assim se obtenham bons resultados, quer ao nível da eficiência, quer ao nível de redução de emissões. A aplicação de barreiras térmicas nas câmaras de combustão previne a perda de calor, aumentando, assim, a eficiência do motor. Por outro lado, a utilização de TBC nos componentes metálicos que se encontram na vizinhança da câmara de combustão permite aumentar as temperaturas de serviço, alcançando maiores eficiências [12]. No campo industrial, vê-se a necessidade de aplicações de revestimentos em diferentes componentes de equipamentos que estão cada vez mais exigentes em termos de desempenho, durabilidade e confiabilidade. Estas características estão direta ou indiretamente relacionadas a qualquer tipo de desgaste (ou perda de massa) e outras possíveis causas de danos, como oxidação, corrosão entre outros. Para melhores resultados dos revestimentos, são estudados e desenvolvidos vários métodos que possam ser utilizados para a aplicação dos revestimentos [1,12].

A aplicação de revestimentos pode ser efetuada por diversos processos, como PVD (Physical Vapour Deposition), CVD (Chemical Vapour Deposition), eletrodeposição e, dentre os processos atualmente com maior desenvolvimento, aspersão térmica. A aspersão térmica consiste em um grupo de processos onde materiais metálicos ou não metálicos, finamente divididos, são depositados em uma condição fundida ou semifundida sobre um substrato preparado, formando um depósito aspergido [1,13]. A pistola de aspersão é um equipamento utilizado para aplicação do revestimento, que utiliza gases combustíveis ou um arco elétrico para gerar o calor necessário, fazendo com que o material sob a forma de pó, arame ou vareta se aqueça até o ponto de fusão, suas partículas são projetadas, por meio de um gás comprimido, contra a superfície do substrato e aderem por impacto e resfriam, transformando-se no revestimento. Esse processo é mostrado esquematicamente na Figura 1.

Ao se chocarem contra a superfície, as partículas se aglomeram e deformam na forma de panquecas (splat) uma sobre a outra, criando uma camada de material consistente sobre o substrato, com porosidade residual. Os revestimentos aspergidos possuem três aspectos básicos [1]: a) substratos: onde os revestimentos são aplicados, incluem metais, óxidos, cerâmicos, vidros, plásticos e madeiras. A preparação antes da aspersão 


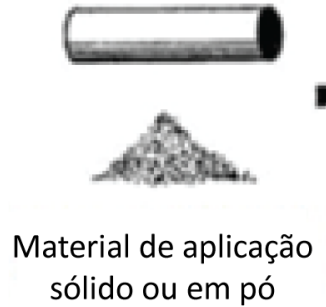
sólido ou em pó
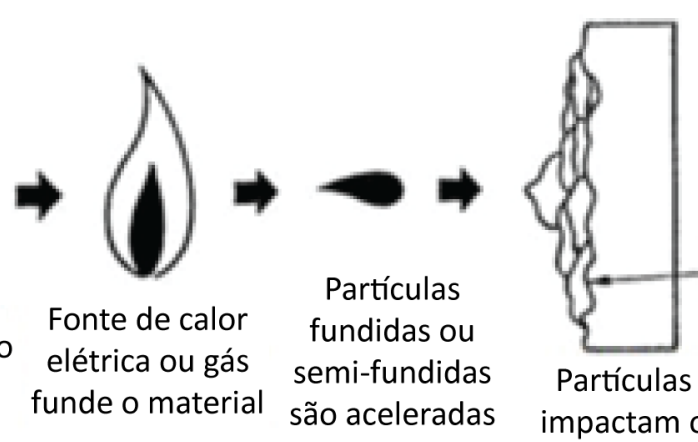

Partículas

impactam o

substrato e

são aplainadas

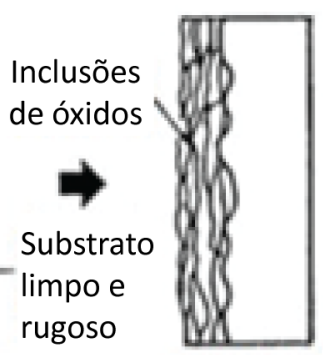

Revestimento concluído

Figura 1. Esquema de aplicação de revestimento por aspersão térmica [1].

é necessária para todas as variações do processo, sendo basicamente a mesma para qualquer aplicação. Tanto a limpeza da superfície, para eliminar a contaminação que inibirá a ligação do revestimento ao substrato, quanto a manutenção de rugosidade superficial, para prover pequenas rugosidades ou irregularidades que permitam a adesão ao revestimento ao criar uma maior área superficial afetiva, são fatores importantes para a aplicação dos revestimentos; b) camada de ligação: a ligação entre o revestimento e o substrato pode ser mecânica, química, metalúrgica, física ou uma combinação destas. A adesão é influenciada por uma série de fatores, tais como: material de revestimento; condição do substrato; grau de rugosidade da superfície; limpeza; temperatura da superfície antes, durante e após a aspersão; e velocidade de impacto da partícula; c) estrutura do revestimento: a estrutura depositada e a química do revestimento aspergido em ar ambiente são diferentes daquelas do mesmo material na forma manufaturada, ou antes, de ser aspergido. A Figura 2 ilustra, esquematicamente, a seção transversal de um revestimento aspergido.

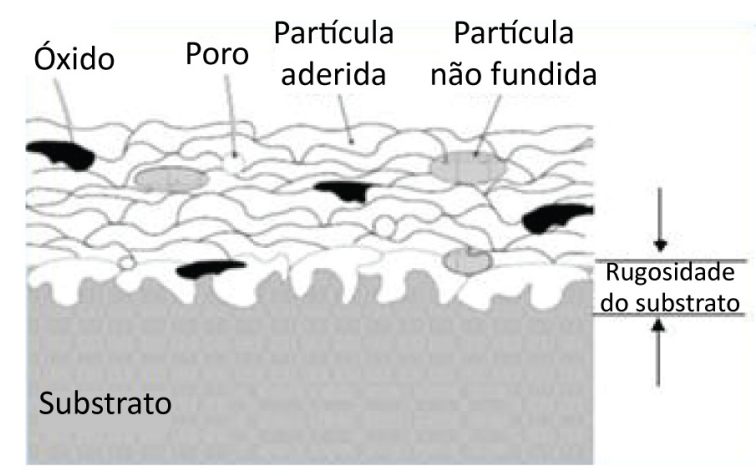

Figura 2. Seção transversal de um revestimento aspergido [14].

Os processos de aspersão térmica podem ser divididos em dois grupos básicos: I) que utiliza combustão (chama) e II) que utiliza energia elétrica como fonte de energia. A aspersão por combustão utiliza gases combustíveis como fonte de calor e, como consumíveis, materiais em forma de pó, arame, vareta ou cordão. Nos processos que empregam a energia elétrica como fonte de calor, os consumíveis são na forma de pó ou arame [1,13].

O processo de aspersão por chama (Flame Spray) utiliza a energia gerada pela combustão de um gás combustível misturado com oxigênio como fonte de aquecimento para fundir o material de deposição, que pode estar em forma de pó ou de arame [1]. Quando utilizado material na forma de pó, a alimentação é geralmente por gravidade, introduzindo-se as partículas axialmente ou radialmente na tocha, com velocidades mínimas. No momento em que ocorre a fusão do pó, ocorre a projeção contra o substrato utilizando um jato de ar comprimido. A Figura 3 ilustra o esquema do Flame Spray, utilizando o pó como consumível. 


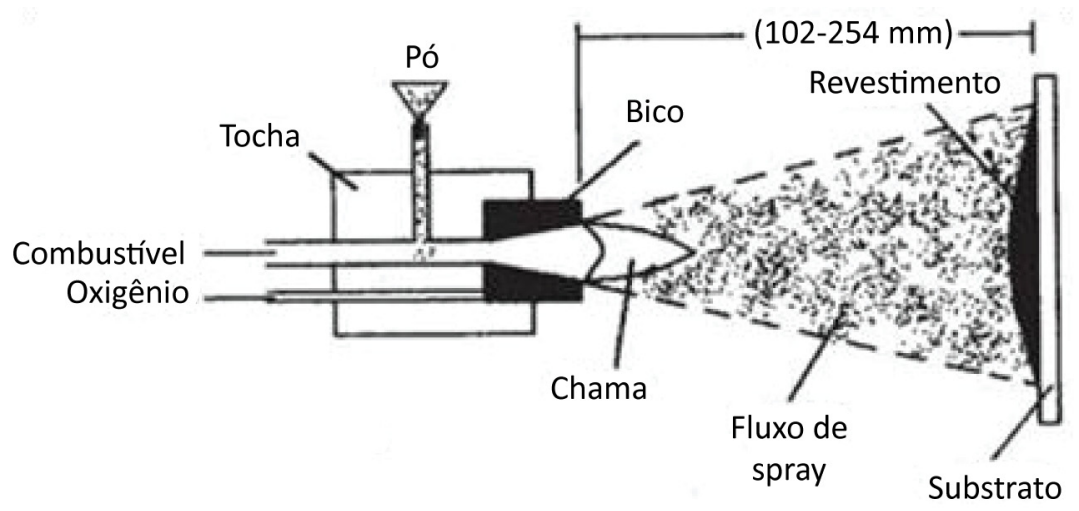

Figura 3. Esquema de aspersão por chama de pós [1].

Neste processo, as partículas oxidam pelo contato com o oxigênio contido no ar comprimido. Os teores de óxidos são variados, 0,4\% [15,16] até 10\% [17], sendo que as referências consultadas não especificam se o material utilizado foi pó ou arame. A porosidade está relacionada com a formação das panquecas e vazios entre as lamelas e partículas depositadas [18]. O pó de alimentação pode ser um metal puro, uma liga, um compósito, uma cerâmica, um carboneto ou qualquer combinação destes, com uma taxa de alimentação que pode variar de 50 a $100 \mathrm{~g} / \mathrm{min}$ e com taxa de fluxo de gás de transporte entre 3 a $5 \mathrm{l} / \mathrm{min}$ [1,13]. Utilizando o método de aspersão por chama de pó, os revestimentos têm menor resistência adesiva e resistência coesiva, maior porosidade, possivelmente por conta da velocidade das partículas serem mais baixas que em outros processos.

Neste trabalho, o objetivo principal foi estudar o comportamento em oxidação a alta temperatura de revestimentos utilizados como camada de ligação (bond coat) em TBCs, aplicados pelo processo mais simples de aspersão, o Flame Spray.

\section{Materiais e Métodos}

Para o desenvolvimento do presente trabalho, foi utilizada uma liga comercial como camada de ligação, em função de seu uso para diversas aplicações industriais. O material utilizado como substrato foi o aço carbono AISI 1020. Os procedimentos realizados no substrato, antes de aplicar a camada de ligação, foram: a) preaquecimento, a uma temperatura de $80^{\circ} \mathrm{C}$. Experiências mostram que pré-aquecer a superfície que será aspergida melhora a adesão do revestimento ao substrato [1,13]; b) limpeza para eliminar eventuais vestígios de substâncias que podem prejudicar a aderência da camada de ligação ao metal base e provocar a rugosidade adequada na superfície a ser aspergida. A limpeza por jateamento abrasivo é a mais recomendada na aspersão térmica; foi utilizado óxido de alumínio para a limpeza da superfície.

O material aplicado foi a liga NiAl em forma de pó, com a composição química mostrada na Tabela 1. O processo empregado para realizar o revestimento do substrato foi o Flame Spray. Com este método, de fácil portabilidade, o material em pó é alimentado para a tocha, proveniente de um reservatório, que pode ser separado da tocha ou montado sobre a mesma [13]. A escolha deste método de aspersão se deu por seu baixo custo operacional e facilidade de aplicação.

Tabela 1. Análise química do material utilizado como camada de ligação.

\begin{tabular}{cc}
\hline Composição & \% peso \\
$\mathrm{Al}$ & 4,65 \\
$\mathrm{Ni}$ & 94,01 \\
Outros & 1,39 \\
\hline
\end{tabular}


O pó fundido pela chama é impingido ao substrato utilizando jato de ar comprimido e tendo como combustível o oxigênio-acetileno. A taxa de alimentação do pó foi de, aproximadamente, $80 \mathrm{~g} / \mathrm{min}$. A distância de aspersão (SOD - Standoff Distance), distância do bico da tocha ao substrato, foi de $150 \mathrm{~mm}$, realizando a aspersão com a chama perpendicular ao substrato.

A rugosidade dos revestimentos foi medida com um rugosímetro eletromecânico Mitutoyo, Surftest 211. Na medição da rugosidade, foram seguidas as orientações dos valores recomendados para o comprimento da amostragem, conforme mostrado na Tabela 2.

Tabela 2. Valores recomendados de comprimento da amostragem, Cut Off [19].

\begin{tabular}{ccc}
\hline Rugosidade Ra $(\boldsymbol{\mu m})$ & Filtro $\boldsymbol{\lambda c}(\mathbf{m m})$ & Comprimento de Avaliação $(\mathbf{m m})$ \\
$\mathrm{Ra} \leq 0,1$ & 0,25 & 1,25 \\
$0,1<\mathrm{Ra} \leq 2$ & 0,80 & 4,00 \\
$2<\mathrm{Ra} \leq 10$ & 2,50 & 12,50 \\
$10<\mathrm{Ra}$ & 8,00 & 40,00 \\
\hline
\end{tabular}

Para o ensaio de oxidação isotérmica, foram utilizados três corpos de prova com mesma dimensão, $30 \times 50 \times 5 \mathrm{~mm}$. Os ensaios de oxidação isotérmicos foram realizados em um Forno Brasimet modelo $\mathrm{DH} 17-\mathrm{A}$ (temperatura máxima de $1500^{\circ} \mathrm{C}$ ), a uma temperatura de $1000^{\circ} \mathrm{C}$ em atmosfera de ar estático, com exposição de 24, 48, 96 horas, respectivamente. As amostras revestidas foram protegidas com um cimento refratário especial, deixando exposto apenas o revestimento nos ensaios de oxidação. Após cada tratamento, as amostras foram retiradas do forno e resfriadas em ar atmosférico à temperatura ambiente. Cada amostra foi pesada antes e após o teste de oxidação, utilizando uma balança digital Gehaka, modelo BG 200, peso máximo de $200 \mathrm{~g}$ e precisão de $0,001 \mathrm{~g}$. As medidas de ganho de massa são relatadas como o aumento de massa em grama para cada amostra.

Para realizar a análise por Microscopia Eletrônica de Varredura e Microscopia Ótica (Nikon, modelo Optphot), os corpos de prova foram embutidos em uma resina sintética (baquelite), utilizando uma prensa metalográfica Arotec, modelo PRE $40 \mathrm{Mi}$, de pressão máxima $350 \mathrm{~kg} / \mathrm{cm}^{2}$. Logo após o embutimento, os corpos de provas foram lixados em uma lixadeira Arotec, modelo APL - 4D, utilizando as lixas 220, 320, 400, 600 e 1200 mesh, visando à remoção de danos provenientes do corte das amostras e a realização de uma superfície plana, cuja profundidade dos riscos visíveis sejam suficientemente finos para que desapareçam após a posterior operação de polimento. No polimento, foi utilizado um pano aveludado e como pasta de polir a alumina $4 \mathrm{Si}$.

\section{Resultados e Discussão}

\subsection{Avaliação da rugosidade}

Para avaliar a rugosidade dos substratos, os parâmetros mais empregados são o Ra e o Ry. Assim, foram empregados esses dois parâmetros para medir a rugosidade do revestimento de NiAl. Para a medição dos valores da rugosidade em $R a$, segundo o acabamento superficial da amostra, foi utilizado o comprimento de amostragem $L$, selecionado na Tabela 2, com o valor de 0,8 mm. Os valores de rugosidade, anotados como o valor médio de 5 medidas nas amostras como aspergidas, são apresentados na Tabela 3.

Tabela 3. Medidas da rugosidade dos revestimentos como aspergidos.

\begin{tabular}{lcccccc}
\hline & Medição 1 & Medição 2 & Medição 3 & Medição 4 & Medição 5 & Média \\
Ra $(\boldsymbol{\mu m})$ & 8,27 & 8,72 & 8,64 & 8,10 & 8,80 & 8,50 \\
$\operatorname{Ry}(\boldsymbol{\mu m})$ & 66,90 & 69,80 & 71,40 & 72,10 & 69,80 & 70,00 \\
\hline
\end{tabular}


A rugosidade obtida no revestimento era esperada uma vez que esta é uma característica inerente ao processo de aspersão térmica por Flame Spray. Segundo a norma Petrobras N-2568, os valores de rugosidade, no caso de um revestimento aplicado por aspersão térmica e substrato de aço ABNT 1020, devem ser Ry > $60 \mu \mathrm{m}$ e $\mathrm{Ra}>6 \mu \mathrm{m}$, para que se possa obter um revestimento com boa aderência [20].

É importante que se mantenha a rugosidade superficial da camada de ligação dentro de valores adequados, pois esta influencia no desempenho do revestimento, como, por exemplo, no estado de tensões após ciclos térmicos em serviço, podendo levar à formação de trincas na interface com a camada cerâmica e eventual desplacamento. A superfície mais lisa permite maior acomodação de tensões térmicas especialmente para as partículas mais esféricas [21]. Em contraposição, a camada de ligação deve apresentar uma superfície rugosa que favorece a resistência adesiva do revestimento [22].

\subsection{Análise da microestrutura}

A Figura 4 mostra a seção transversal típica do revestimento obtido por aspersão térmica. A espessura média das camadas obtidas foi avaliada em $300 \mu \mathrm{m}$, antes do ensaio de oxidação isotérmica.

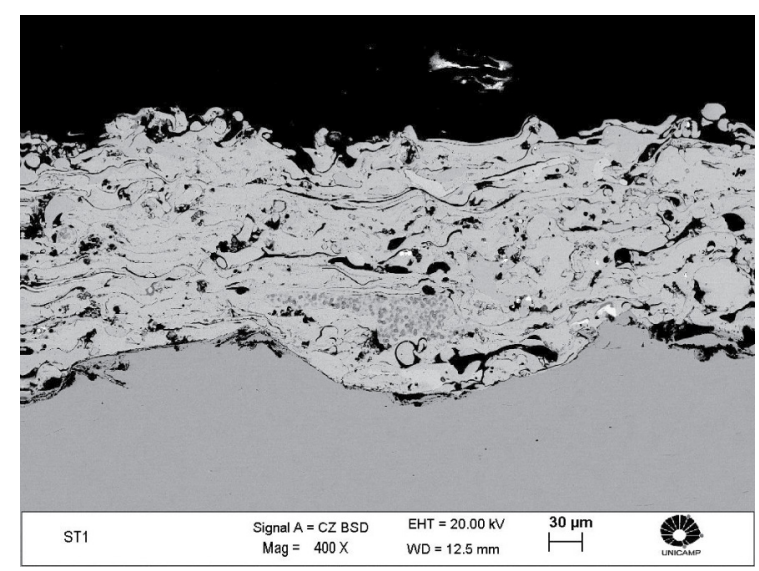

Figura 4. Imagem de Microscopia Eletrônica de Varredura da seção transversal do revestimento NiAl.

A microestrutura do revestimento é lamelar, podendo-se identificar as partículas de alumínio (fase escura) na matriz de níquel. Pode-se, ainda, verificar uma boa adesão do revestimento ao substrato de aço carbono, com alguma presença de óxido na interface.

\subsection{Ensaio de oxidação}

A resistência à oxidação foi avaliada pela variação de massa das amostras. Antes da exposição a alta temperatura, foram feitas três pesagens para cada uma das amostras, utilizando-se a balança digital. Os valores medidos e as médias dos mesmos são listados na Tabela 4 para a pesagem inicial antes do teste.

Tabela 4. Massa das amostras antes do ensaio de oxidação isotérmico.

\begin{tabular}{|c|c|c|c|c|}
\hline \multirow{2}{*}{ Amostra } & \multicolumn{4}{|c|}{ Peso antes do ensaio em g - Tempo (0 h) } \\
\hline & Medida 1 & Medida 2 & Medida 3 & Média $\left(m i{ }_{n}\right)$ \\
\hline 1 & 61,425 & 61,426 & 61,422 & 61,424 \\
\hline 2 & 60,979 & 60,978 & 60,979 & 60,979 \\
\hline 3 & 62,023 & 62,028 & 62,026 & 62,026 \\
\hline
\end{tabular}


O ganho de massa foi determinado de acordo com a Equação 1 para as amostras revestidas, chamadas de $\Delta m 1, \Delta m 2, \Delta m 3$, respectivamente.

$$
\Delta m_{n}=m f_{n}-m i_{n}
$$

Onde: $\Delta m_{n}=$ variação de massa das amostras; $m f_{n}=$ massa final das amostras (depois da exposição à alta temperatura); $m i_{n}=$ massa inicial amostras (antes da exposição à alta temperatura). Os resultados do ganho de massa podem ser observados na Tabela 5.

Para uma melhor visualização dos dados apresentados na Tabela 5, é apresentado o gráfico da Figura 5.

Tabela 5. Massa das amostras após ensaio de oxidação isotérmico.

\begin{tabular}{|c|c|c|c|c|c|}
\hline Amostra & \multicolumn{4}{|c|}{ Peso após ensaio (g) - Tempo (24 h) } & $\begin{array}{c}\text { Ganho de Massa } \\
\text { (g) }\end{array}$ \\
\hline \multirow{2}{*}{1} & Medida 1 & Medida 2 & Medida 3 & Média $\left(m f_{1}\right)$ & $\Delta \mathrm{m} 1$ \\
\hline & 63,126 & 63,124 & 63,122 & 63,124 & 1,700 \\
\hline \multicolumn{6}{|c|}{ Peso após ensaio (g) - Tempo (48 h) } \\
\hline \multirow{2}{*}{2} & Medida 1 & Medida 2 & Medida 3 & Média $\left(m f_{2}\right)$ & $\Delta \mathrm{m} 2$ \\
\hline & 62,971 & 62,973 & 62,973 & 62,972 & 1,994 \\
\hline \multicolumn{6}{|c|}{ Peso após ensaio (g) - Tempo (96 h) } \\
\hline \multirow{2}{*}{3} & Medida 1 & Medida 2 & Medida 3 & Média $\left(m f_{3}\right)$ & $\Delta \mathrm{m} 3$ \\
\hline & 65,879 & 65,878 & 65,879 & 65,879 & 3,853 \\
\hline
\end{tabular}

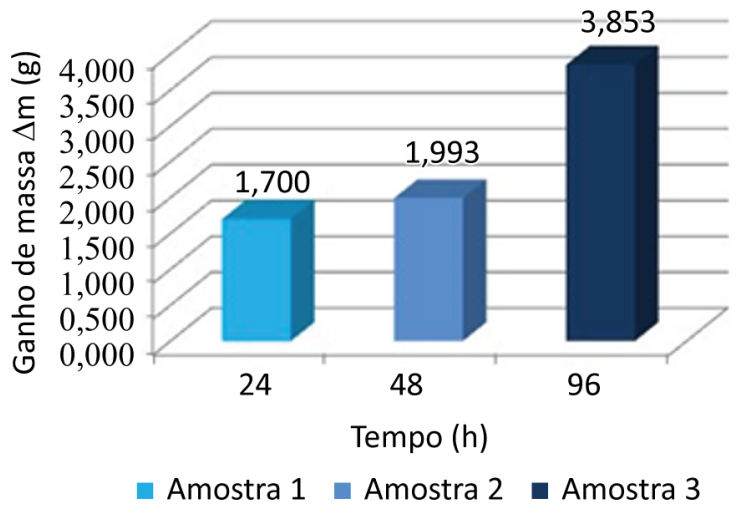

Figura 5. Ganho de massa das amostras expostas no forno a uma temperatura de $1.000{ }^{\circ} \mathrm{C}$ com intervalos de tempo de 24, 48 e 96 horas.

De modo geral, houve um aumento significativo da oxidação, podendo-se notar que o ganho de massa aumenta com o tempo de exposição, como esperado para o experimento proposto. Comparando as amostras, observa-se que a amostra 2 com exposição duas vezes maior que a amostra 1 teve um ganho de massa adicional de apenas $17 \%$, refletindo uma possível oxidação preferencial nas primeiras horas do teste. Ensaios realizados com a presença da camada externa cerâmica sobre a camada de ligação mostram que a maior taxa de oxidação ocorre logo nas primeiras 12 horas o teste [23]. A amostra 3, que ficou exposta por 96 horas, foi a que teve maior ganho de massa, quase o dobro da amostra exposta 48 horas (amostra 2). Resultados demonstram que ensaios de oxidação em altas temperaturas (acima de $900^{\circ} \mathrm{C}$ ) com aumento sistemático do tempo de exposição provocam aumento na quantidade de óxido formado que pode ser confirmado pela variação da massa medida [24] No caso da amostra exposta por 96 horas, o grande aumento de massa pode estar também relacionado com a oxidação adicional na interface com o substrato, formando outros óxidos de maior massa que a alumina basicamente formada na superfície externa. 
A Figura 6 mostra imagens do estado superficial das amostras após o ensaio de oxidação isotérmica.

A Figura 7 mostra as imagens de seção transversal dos revestimentos após o ensaio de oxidação isotérmica, podendo ser identificadas as características de oxidação em cada tempo de exposição. Como esperado, as amostras sofreram severa oxidação superficial que alcançou mais de $60 \mu \mathrm{m}$ de espessura logo após as primeiras 24 horas (Figura 7a) e, com o aumento do tempo de exposição, a espessura não aumentou significativamente, havendo inclusive uma deterioração e desintegração incremental (Figura 7b, c) da camada de óxido exposta ao ambiente do forno. Adicionalmente, ocorreu a oxidação na interface com o substrato, levando ao completo desplacamento do revestimento após 96 horas (Figura 7c). Observa-se, ainda, um aumento da oxidação nas lamelas internas do revestimento, em especial na fase $\mathrm{Al}$, como pode ser observado com maior detalhe na imagem ampliada da Figura 8. A evolução da oxidação gera um nível elevado de tensões residuais em função das diferenças de expansão térmica das distintas fases. Estas tensões levam, finalmente, à geração e propagação de trincas que causam a fratura do revestimento e consequente desplacamento.
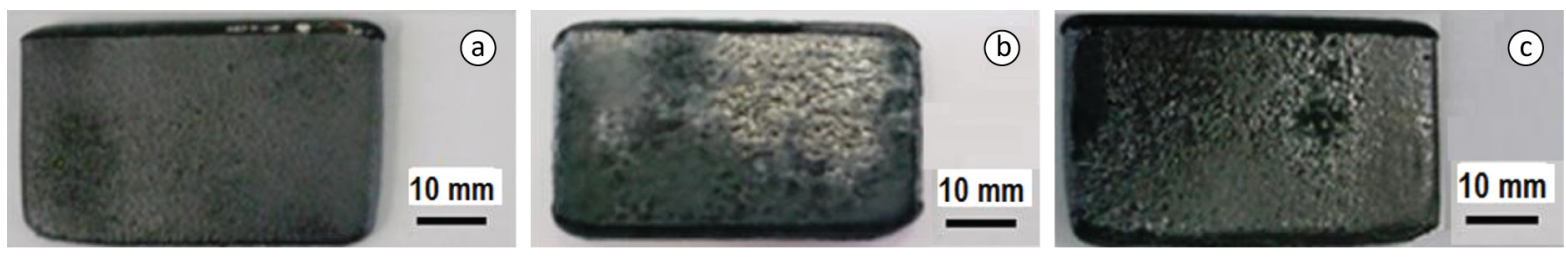

Figura 6. Imagens da superfície das amostras após ensaio de oxidação isotérmica com tempos de exposição de (a) 24 horas, (b) 48 horas e (c) 96 horas.
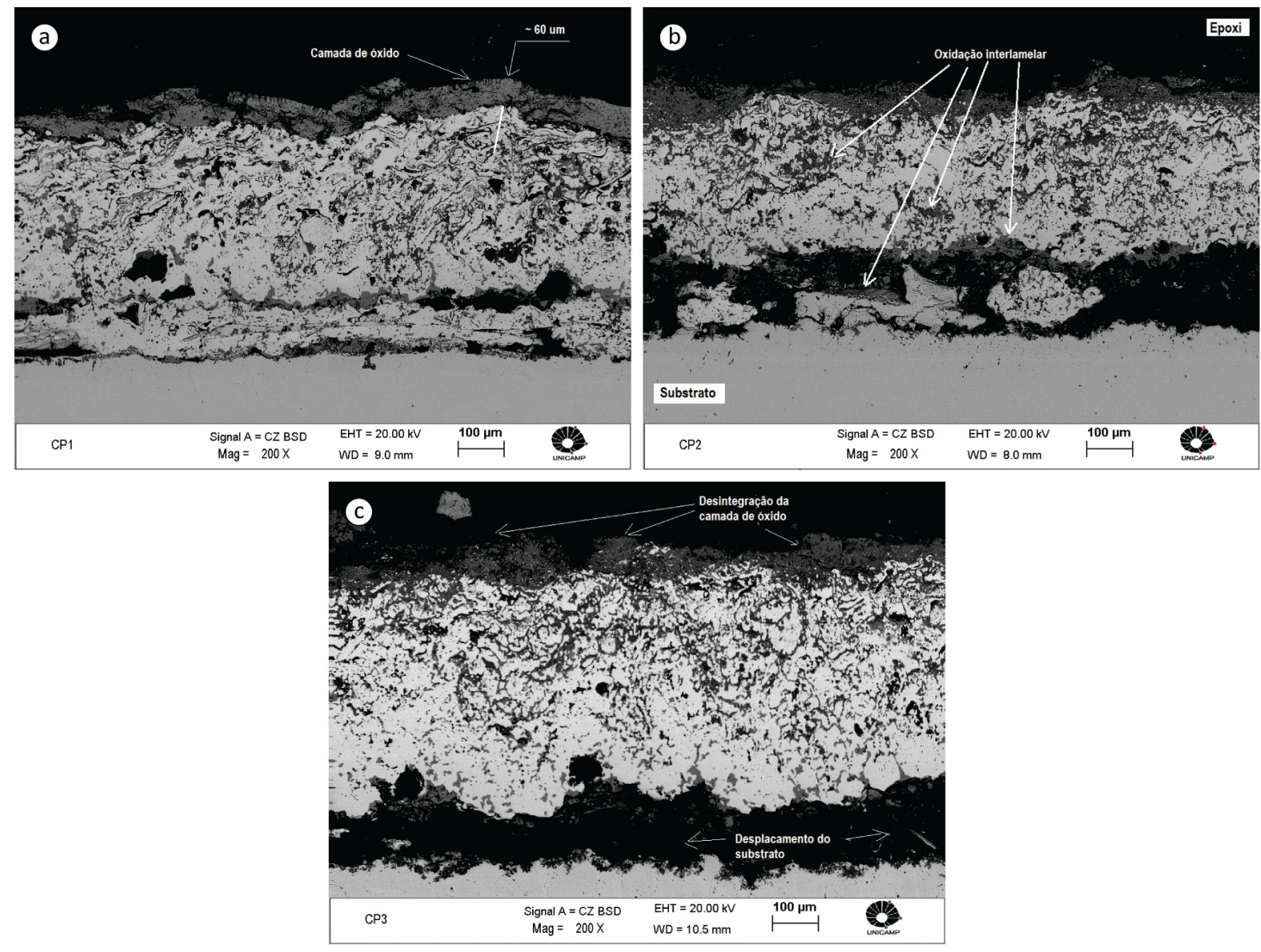

Figura 7. Imagens de Microscopia Eletrônica de Varredura da seção transversal das amostras expostas a oxidação isotérmica durante (a) 24 horas, (b) 48 horas e (c) 96 horas. 
Nas análises de MEV, foi possível visualizar a separação entre o bond coat e o substrato (Figura 7c), o que se propões ser acelerada pelo grande número de vazios gerados nessa região, possivelmente pelo efeito Kirkendall, ou seja, desbalanceamento na difusão de materiais distintos ( $\mathrm{Ni}, \mathrm{Al}$ ) com fluxo de átomos de um material para outro, deixando vazios nesta região, como detalhado na Figura 8b. Fato semelhante foi observado em estudos onde foram depositadas ligas $\mathrm{NiAl}$ sobre substratos de Inconel 600 , submetidas a ciclos térmicos a $1100^{\circ} \mathrm{C}$. Verificou-se que, após vários ciclos, formou-se um grande número de vazios na interface do bond coat com o substrato. $\mathrm{O}$ aumento excessivo de vazios e difusão de poros na interface do revestimento pode prejudicar a aderência do revestimento, levando ao desplacamento do bond coat do substrato $[25,26]$.
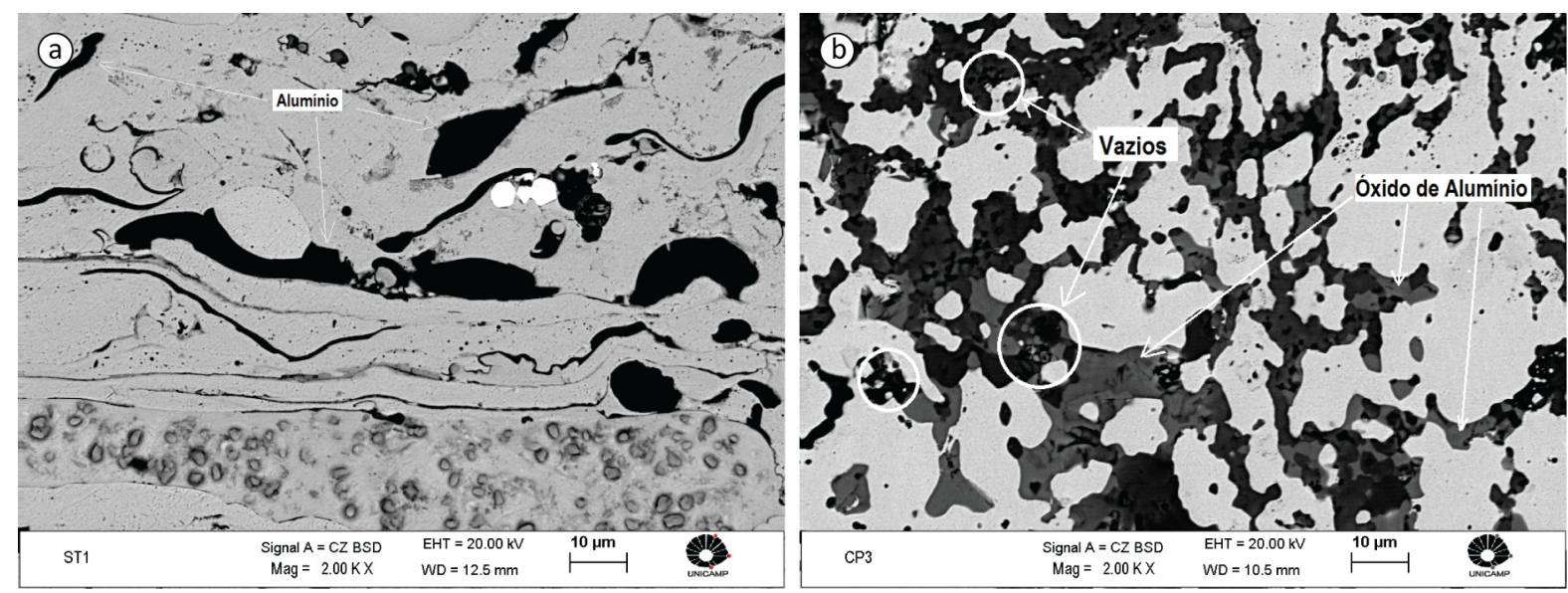

Figura 8. Imagens de Microscopia Eletrônica de Varredura da seção transversal das amostras (a) como aspergida e (b) exposta a oxidação isotérmica durante 96 horas. Intensa oxidação pode ser observada especialmente na fase alumínio do revestimento, com formação de alumina.

\section{Conclusões}

Amostras de aço carbono revestidas com NiAl foram submetidas a oxidação isotérmica a uma temperatura de $1000{ }^{\circ} \mathrm{C}$.

De modo geral, houve um aumento significativo da oxidação, podendo-se notar que o já esperado ganho de massa em correlação com o aumento do tempo de exposição, porém não de forma proporcional, visto que a variação entre 24 e 48 horas (17\%) é bem menor que a variação de 48 para 96 horas de exposição, quando o ganho de massa é praticamente duplicado nas 48 horas finais.

Houve desplacamento total do revestimento após 96 horas de exposição, iniciado pelo aumento da oxidação na interface com o substrato de aço carbono.

\section{Agradecimentos}

Os autores agradecem o apoio financeiro do CNPq e a OGRAMAC Engenharia de Superfícies, pelo apoio técnico na execução dos revestimentos.

\section{Referências}

[1] Lima CRC, Trevisan RE. Aspersão térmica: fundamentos e aplicações. 2a. ed. São Paulo: Artliber; 2007. 152 p.

[2] Almeida DS. Estudo de revestimentos cerâmicos sobre substrato metálico, obtidos por deposição físico de vapores por feixe elétrons para aplicação como barreira térmica [tese de doutorado]. São José dos Campos: INPE; 2005. p. 175-177.

[3] Hill MD, Domingues LP. Creating a effective barrier. Ceramic Industry. 2003;153(10):17-19.

[4] Hass DD. Thermal barrier coatings via directed vapor deposition [doctor degree]. Charlottesville: University of Virginia; 2001.

[5] Zhu D, Miller RA. Thermal barrier coating for advanced gas turbine and diesel engines. Ohio: NASA; 1999. 12 p. NASA/ TM-1999-209453.

[6] Zhu D, Miller RA, Nagaraj BA, Bruce RW. Thermal conductivity of EBPVD thermal barrier coatings evaluated by a steady-state 
laser heat flux technique. Ohio: NASA; 2000. 18 p. NASA/ TM-2000-210238.

[7] Jamarani F, Korotkin M, Lang RV, Ouellette MF, Yan KL, Bertram $\mathrm{RW}$, et al. Compositionally graded thermal barrier coatings for high temperature aero gas turbine components. Surface and Coatings Technology. 1992;54-55:58-63. http://dx.doi. org/10.1016/S0257-8972(09)90028-7.

[8] Schulz U. Phase transformation in EB-PVD yttria partially stabilized zirconia TBCs during annealing. Journal of the American Ceramic Society. 2000;4(83):904-910.

[9] Schulz U, Leyens C, Fritscher K, Peters M, Saruhan-Brings B, Lavigne $\mathrm{O}$, et al. Some recent trends in research and technology of advanced TBCs. Aerospace Science and Technology. 2003;7(1):7380. http://dx.doi.org/10.1016/S1270-9638(02)00003-2.

[10] Hejwowski T, Weroński A. The effect of Thermal Barrier Coatings on diesel engine performance. Vacuum. 2002;65(3-4):427-432. http://dx.doi.org/10.1016/S0042-207X(01)00452-3.

[11] Taymaz I. The effect of thermal barrier coatings on diesel engine performance. Surface and Coatings Technology. 2007;201(911):5249-5252. http://dx.doi.org/10.1016/j.surfcoat.2006.07.123.

[12] Ribeiro AJRF. Barreiras térmicas compósitas obtidas por projeção térmica [dissertação de mestrado]. Aveiro: Universidade de Aveiro; 2009. 56 p. [acesso em 2015 dez. 15]. Disponível em: http://biblioteca.versila.com/2759791

[13] Davis JR. Handbook of thermal spray technology. New York: ASM International; 2004. 338 p.

[14] Marques PV. Aspersão térmica. Belo Horizonte: Infosolda; 2003. $16 \mathrm{p}$.

[15] Fauchais P, Heberlein JVR, Boulos MI. Thermal spray fundamentals: from powder to part. New York: Springer; 2014.

[16] Kreinbuehl R, Kunzmann and Wilmer, K. Corrosion protection by arc sprayed al: new developments. Switzerland: Swiss Aluminium; 1974.

[17] Britton CR. Flame spraying with aluminium and aluminium alloys. Revista Aluminium Industry. 1988;7(10):1-3.
[18] Pawlowski L. The science and engineering of Thermal Spray Coatings. 2a ed. Chichester: John Wiley \& Sons; 2008.

[19] Associação Brasileira de Normas Técnicas. ABNT NBR ISO 4287:2002. Especificações geométricas do produto (GPS) Rugosidade: método do perfil-Termos, definições e parâmetros de rugosidade. Rio de Janeiro: ABNT; 2002.

[20] Comissão de Normas Técnicas. N-2568. Seleção e aplicação (por aspersão térmica) do alumínio, zinco e suas Ligas como revestimento anticorrosivo. Rio de Janeiro: Petrobrás; 1996. $34 \mathrm{p}$.

[21] Haynes JA, Unocic KA, Lance MJ, Pint BA. Impact of superalloy composition, bond coat roughness and water vapor on TBC lifetime with HVOF NiCoCrAIYHfSi bond coatings. Surface and Coatings Technology. 2013;237:65-70. http://dx.doi.org/10.1016/j. surfcoat.2013.09.062.

[22] Knight R, Zhangxiong D, Kim EH, Smith RW, Sahoo P, Bucci D. Influence of bond coat surface characteristics on the performance of TBC systems. In: Coddet C. Thermal spray: meeting the challenges of the 21st century. Ohio: ASM International; 1998, p. 1549-1554.

[23] Lima CRC, Cinca N, Guilemany JM. Study of the high temperature oxidation performance of Thermal Barrier Coatings with HVOF sprayed bond coat and incorporating a PVD ceramic interlayer. Ceramics International. 2012;38(8):6423-6429. http://dx.doi. org/10.1016/j.ceramint.2012.05.016.

[24] Callister JR, William D. Ciência e engenharia dos materiais: uma introdução. 1a. ed. Rio de Janeiro: LTC; 2002.

[25] Huang KJ, Chang JT, Davison A, Chen KC, He JL, Lin CK, et al. Thermal cyclic performance of NiAl/Alumina stabilized zircon thermal barrier coatings deposited using a hybrid arc and magnetron sputtering system. Surface and Coatings Technology. 2006;201(7):3901-3905. http://dx.doi.org/10.1016/j. surfcoat.2006.07.259.

[26] Reddy A, Hovis DB, Heuer AH, Paulikas AP, Veal BW. In situ study of oxidation-induced growth strains in a model NiCrAlY bond-coat alloy. Oxidation of Metals. 2007;67(3-4):153-177. http://dx.doi.org/10.1007/s11085-006-9044-8. 